\title{
ПРАВОВАЯ ПРИРОДА ПЕРЕДАЧИ ВЕЩИ КАК ЭЛЕМЕНТА ФАКТИЧЕСКОГО СОСТАВА РЕАЛЬНОГО ДОГОВОРА
}

\author{
Т. В. Ламм, Е. В. Титов \\ Байкальский государственный университет, г. Иркутск, Российская Федерация
}

\author{
Информация о статье \\ Дата поступления \\ 18 мая 2017 г. \\ Дата принятия к печати \\ 20 ноября 2017 г. \\ Дата онлайн-размещения \\ 27 ноября 2017 г.

\section{Ключевые слова} \\ Юридический поступок; \\ юридический факт; передача \\ вещи; реальный договор; \\ юридический состав
}

\begin{abstract}
Аннотация
В статье обсуждаются различные точки зрения на правовую природу передачи вещи в реальном договоре. Согласно действующему законодательству, без такой передачи договор не считается заключенным. Однако на практике данное законодательное правило вызывает немало вопросов, связанных с тем, что само соглашение и его «реальная» часть неизбежно разорваны во времени. Один из ключевых вопросов - является ли передача вещи элементом (атрибутом) сделки, самостоятельным юридическим фрактом, фрактическим действием или элементом фрактического состава реального договора. Делается вывод, что передача вещи в реальном договоре по правовой природе является юридическим поступком, включенным в фактический состав договора. Обосновывается, что такая передача является отлагательным условием действительности сделки, предусмотренным законом (condicio iuris).
\end{abstract}

\section{THE LEGAL NATURE OF THE TRANSFER OF OBJ ECTS AS AN ELEMENT OF THE SET OF FACTS OF THE REAL CONTRACT}

\author{
Tatyana V. Lamm, Eugeny V. Titov \\ Baikal State University, Irkutsk, Russian Federation
}

\section{Article info}

Received

May 18, 2017

Accepted

November 20, 2017

Available online

November 27, 2017

\section{Keywords}

Legal act; legal fact; the transfer of things; a real contract; the legal structure of the

\begin{abstract}
The article discusses different points of view on the legal nature of the transfer of things in the real contract. According to the current legislation, without such transfer the contract shall not be formed. However, in practice this legislative rule raises many questions, because the agreement itself and its "real» part are inevitably separated in time. One of the key questions is whether the passing of an object is an element (attribute) of the transaction, a separate legal fact, an actual act or an element of the actual composition of the contract. The conclusion is that the transfer of things in the real contract is, in its legal nature, a legal act included in the actual contract. It is proved that such transfer is a suspensive condition of the validity of a transaction, stipulated by the law (condicio iuris).
\end{abstract}

Правовая природа передачи вещи в реальном договоре оценивается учеными-правоведами и юристами-практиками по-разному. Некоторые авторы квалифицируют такую передачу как элемент договора [1, с. 17], соответственно, имеющую сделочную природу, другие же, напротив, заявляют, что передача вещи и сделка - явления разного рода [2, с. 92-95]. Так, В. В. Груздев называет передачу вещи наряду с собственно выражением воли конститутивным элементом реального договора [3]. Подобного мнения придерживается и С. В. Сарбаш [4, с. 24-80, 128].

Определение правовой природы передачи вещи в реальном договоре необходимо для решения ряда теоретических и практических задач, в частности о возможности применения к передаче вещи правил о соответствующем типе юридических фрактов (например, норм о сделках) - возможности признания передачи вещи недействительной, передачи вещи под условием, форме передачи и т. п.

В зависимости от момента, с которого договор считается заключенным, договоры традиционно разделяют на реальные и консенсуальные (ст. 433 ГК РФ) ${ }^{1}$. Так, к реальным

1 Гражданский кодекс Российской Федерации (часть первая) : федер. закон от 30 нояб. 1994 г. № 51 Ф3 (ред. от 28 марта 2017 г.) // Собрание законодательства РФ. 1994. № 32. Ст. 3301. 
договорам относятся договор займа - абзац 2 п. 1 ст. 807 ГК РФ², реального дарения ст. 572 ГК РФ, хранения - ст. 886 ГК РФ, доверительного управления - ст. 1012 ГК РФ, банковского вклада - ст. 834 ГК РФ, перевозки - ст. 785 и 786 (к реальным договорам традиционно относят также некоторые разновидности договоров аренды, страхования и др. [5]).

Кроме того, существуют «особые» разновидности реальных договоров; например, договор энергоснабжения ${ }^{3}$ с гражданином считается заключенным «с момента первого фрактического подключения абонента в установленном порядке к присоединенной сети» (п. 1 ст. 540 ГК РФ). В подобного рода договорах нет собственно передачи вещи и правила о реальных договорах применимы к ним лишь по аналогии. Для настоящей статьи ключевым является вопрос о правовой природе именно передачи вещи, в связи с чем под реальным договором далее по тексту настоящей статьи понимаются только те из них, которые связаны с передачей вещи.

Реальные договоры - конструкция, заимствованная российским правопорядком из римского права. Данную конструкцию реципировали большинство стран романо-германской правовой семьи, причем без существенных преобразований, практически в неизменном виде, в связи с чем появляется необходимость в исследовании классической юриспруденции в целях ответа на вопросы, для чего была введена данная правовая конструкция, в чем ее особенности и какова природа разграничения реальных и консенсуальных договоров. Все это, как представляется, позволяет глубже и точнее определить правовую природу передачи вещи в реальном договоре. Так, в Древнем Риме заем, залог,

2 Гражданский кодекс Российской Федерации (часть вторая) : федер. закон от 26 янв. 1996 г. № 14Ф3 (ред. от 28 марта 2017 г.) // Собрание законодательства РФ. 1996. № 5. Ст. 410.

${ }^{3}$ Как видно, специфика определяется предметом соглашения - энергия, которая, разумеется, не является вещью, а следовательно, не может быть поставлен вопрос и о передаче вещи. Однако, ввиду того что «подключение» по природе является материальным, утилитарным (полезным) действием реального свойства, представляется возможным распространение правил п. 2 ст. 433 ГК РФ и ст. 224 ГК РФ по аналогии и к такой «передаче». Кроме того, объектом доверительного управления (ст. 1013 ГК РФ) могут быть не только вещи, «переданные» в управление, но и другое «имущество». Очевидно, что «передача» объекта, не являющегося вещью (например, права), не более чем метафора. Законодатель употребляет здесь термин «передача имущества» в наиболее широком смысле: это не только традиция (лат. traditio) (ст. 223, 224 ГК РФ), но и вообще всякое «вручение». ссуда, поклажа являются классическими примерами реальных контрактов [6, с. 550-566]. Конструкция реального контракта предполагала, что обязательство не возникает, пока вещь не передана [там же, с. 550].

Согласно римской юриспруденции, соглашения бывают re (лат. - вещь, т. е. заключаемые посредством передачи вещи (реальные)); litteris (лат. - посредством письма, в письменной форме); verbis (лат. - заключаемые в форме произнесения особого набора слов (устно)) и consensu (лат. - заключаемые посредством соглашения (консенсуальные) $)^{4}$. Последние не обладают «формализмом» и заключаются в наиболее свободной форме - посредством «голого соглашения» (лат. nuda consensu), совершения никаких дополнительных действий для действительности такого волеизъявления не требовалось 5 . Напротив, для действительности первых трех разновидностей соглашений соответственно требовались передача вещи, запись в специальной книге либо произнесение торжественных слов. Однако достижение соглашения необходимо в любом случае ${ }^{6}$, т. е. реальный договор состоит из двух действий - соглашения (лат. conventio), существующего в любом договоре, и передачи вещи (лат. re).

Согласно современной трактовке, договор - взаимное волеизъявление сторон ${ }^{7}$

${ }^{4}$ Paul. $3^{\text {rd }}$ ed. D. 2,14,2. Выдержки из Дигест Юстиниана здесь и далее по тексту приведены по: [7, с. 17].

${ }^{5}$ Можно заметить, что современное право не лишено римского "формализма», помимо реальных договоров наш правопорядок знает также и литеральные (разумеется, с учетом современных особенностей), например п. 2 ст. 162, ст. 331, 339, 362, 434, 550, 560, 651,680 ГК РФ. Отсутствует разве что наиболее древняя форма - вербальных соглашений, зато появляется нотариальная форма и государственная регистрация сделок (аналоги которых, разумеется, были и в Риме - манципация (лат. mancipatio) и уступка перед магистратом (лат. in iure cessio)). Выделение особого рода реальных договоров характерно для континентальной (римской) правовой семьи, американский и некоторые европейские правопорядки понимают под договором исключительно соглашение без дополнительных формальностей, зачастую и без требований к форме. Например: ст. II. - 4:101 DCFR (Модельные правила европейского частного права), ст. 3.1.2 РІСС (Принципы международных коммерческих договоров УНИДРУА), п. 2 ст. 2:101 PECL (Принципы европейского контрактного права), ст. IV.2.1 TLP (Принципы СЕНТРАЛ).

6 Так, Ульпиан в 4-й книге «Комментариев к эдикту» пишет: «Слово conventio (соглашение) является настолько общим, что, как хорошо сказал Педий, нет никакого контракта, никакого обязательства, где бы ни содержалось соглашения, в зависимости от того, совершается ли оно посредством передачи вещи или посредством слов, ибо и стипуляция, которая совершается посредством слов (verbis. - T. Л., E. T.), ничтожна, если нет согласия» (см.: Ulp. 4hd ed. D. 2,14,1,3).

7 Особенно показательным является п. 2 ст. II. 1:101 DCFR, определяющий понятие юридического 
[8, с. $18 ; 9$, с. 26-37], порождающее обязательственную связь ${ }^{8}$, т. е. не что иное, как римское conventio (п. 3 ст. 154 ГК РФ). Такое понимание договора в полной мере соответствует классическому представлению о моменте, с которого договор считается заключенным: римский юрист всегда скажет, что договор считается заключенным с момента, когда стороны пришли к согласию - консенсусу ${ }^{9}$, т. е. только в момент, указанный в п. 1 ст. 433 ГК РФ, - момент акцепта оферты. Но для достижения желаемых правовых последствий, преследуемых сторонами договора, бывает недостаточно одного лишь соглашения (nuda consensu). В реальном договоре без передачи вещи договор не порождает правовых последствий - не возникает обязательства. Передача вещи в данном случае является необходимым условием (заложенным в конструкцию соглашений соответствующего типа самим правопорядком - condicio iuris) вступления соглашения (уже существующего!) «в силу» ${ }^{10}$. Такого же мнения придерживаются, в частности, Б. Л. Хаскельберг и В. В. Ровный $[10$, c. 63-66].

Современное гражданское законодательство России указывает на то, что реальный договор именно "считается заключенным» с момента передачи вещи (п. 2 ст. 433, абзац 2 п. 1 ст. 807 ГК РФ). В связи с чем в юридической литературе и судебной практике ${ }^{11}$ возникают мнения, что передача вещи есть элемент договора, что, в свою очередь, позволяет квалифицировать и саму передачу

акта: «Юридическим актом признается заявление или соглашение, выраженное прямо или предполагаемое в силу поведения, непосредственно направленное на создание правовых последствий». К подобному выводу можно прийти и при трактовке § 116-157 Гражданского уложения Германии от 18 августа 1896 г. (ред. от 31 марта 2013 г.).

8 Разумеется, не всякое соглашение имеет полный правовой эффрект - обязанность, требование, притязание (нем. - Ansprüche). Некоторые взаимные волеизъявления порождают эксцепции (см.: Ulp. $4^{\text {th }}$ ed. D. $2,14,7)$.

${ }^{9}$ Примирению (расtum - соглашение от лат. рах мир) - соглашаться, «сходиться» на одном (от лат. conventio - сходиться) (см.: Ulp. $4^{\text {th }}$ ed. D. $2,14,1,1$; $2,14,1,3)$.

10 А «силой» такого соглашения является обязательственная связь, соответственно, до передачи вещи договор «бессилен» - лишен правовых последствий, недействителен. Интересно, что при несоблюдении формы сделки современный законодатель совершенно верно квалифицирует их в качестве недействительных (ст. 162, п. 3 ст. 163 ГК РФ): сделка есть, но нет правовых последствий, что, однако, вступает в противоречие со ст. 434 ГК РФ.

11 Обзор судебной практики по спорам, связанным с признанием договоров незаключенными : информ. письмо Президиума ВАС РФ от 25 фревр. 2014 г. № 165 // Вестник ВАС РФ. 2014. № 4. в качестве договора (или, во всяком случае, сделки) [11, с. 120]. Иной вывод противоречил бы формальной логике: часть целого не может по форме и содержанию отличаться от самого целого. Часть договора непременно должна носить сделочную природу быть волеизъявлением ${ }^{12}$.

Следует отметить, что данный подход полностью соответствует закону, однако следование данной логике приводит к логическому противоречию. Передача вещи требует основания (лат. causa) $[12$, S. 1] — iusta causa traditionis (от лат. - законное основание для передачи), таким основанием является не что иное, как сделка. Но если договор до передачи считается незаключенным, то до его заключения отсутствует основание для передачи, а основание - договор - может возникнуть, в силу п. 2 ст. 433 ГК РФ, не ранее самой передачи. Ввиду того что передача и сделка (основание) - явления разного порядка (первое - действие материальное, реальное, тогда как сделка - выражение воли посредством произнесения слов, жестов и иных "знаков», позволяющих "обнаружить волю»), они неизбежно разорваны друг с другом во времени. Получается, что реальный договор не может появиться раньше передачи (согласно закону), передача не может быть раньше основания (договора), одновременное же их «появление» противоречит их "существу»"

Сделка совершается в форме волеизъявления и в момент совершения волеизъявления. Поскольку договор - обмен волеизъявлениями, то в его состав ничего, кроме собственно волеизъявлений, входить не может. Передача вещи не является волеизъявлением, поэтому в состав «обмена волеизъявлениями» не входит ${ }^{14}$. Реальный договор до

12 Уже из этих рассуждений видно, что передача частью соглашения не является.

${ }^{13}$ Данное противоречие порождает немало теоретических и практических проблем. В последнее время все чаще можно заметить, как законодатель отказывается от конструкции «незаключенного» договора (см., напр.: п. 77 ст. 1 закона «О внесении изменений в часть первую Гражданского кодекса Российской Федерации» от 8 марта 2015 г. № 42-Ф3 (Собрание законодательства РФ. 2015. № 10)). Интересные рассуждения по данной проблеме можно найти и в современной юридической литературе [13]. Кроме того, судебная практика позволяет распространить данные нормы и на правоотношения, возникшие до внесения соответствующих изменений в ГК РФ и даже до формирования правовой позиции ВАС РФ по данному вопросу (см., напр.: Определение Верховного Суда РФ от 16 февр. 2017 г. № 309-ЭС 16-14273 [Электронный ресурс] // СПС «КонсультантПлюс». Документ опубликован не был).

${ }^{14}$ П. А. Варул и Л. Я. Халлик утверждают, что волеизъявление является составным элементом сделки, 
передачи вещи необходимо считать заключенным ${ }^{15}$, но не порождающим правовые последствия. Правовые последствия реального договора наступают в силу совокупности юридических фрактов - соглашения (сделки) и передачи вещи (еще одного, отличного от первоначального соглашения действия).

Любой договор - это consensus ${ }^{16}$, реальные договоры не являются разновидностью собственно договоров, поскольку состав реального и консенсуального договора полностью идентичен, значимость такой классификации заключается лишь в определении момента возникновения правовых последствий. Так, если правовые последствия в консенсуальном договоре возникают непосредственно при достижении соглашения, то в фактический состав реального договора добавляется еще один юридический фракт - передача вещи ${ }^{17}$. С такой передачей связывается лишь момент наступления правовых последствий, накопление полного «фактического состава».

Таким образом, до совершения передачи вещи реальный договор «заключен» ${ }^{18}$, но не порождает правовых последствий. Поскольку только обстоятельства реальной действительности, влекущие правовые последствия, являются юридическими фактами, то реальный договор до передачи вещи не может считаться юридическим фрактом и является

куда наряду с ним может входить еще одно или несколько волеизъявлений, реальные акты и даже «содействие органов государственной власти». Однако, как представляется, все это не является элементами сделки, это внешние обстоятельства, наличие которых, безусловно, может иметь значение для действительности сделки [14, с. 13-14].

${ }^{15}$ Договор - это юридический фракт, т. е. фракт реальной действительности. Словосочетание «заключили договор» означает, что взаимно обменялись волеизъявлениями. Это относится к фактическому (существующему в действительности), а отрицать существующее, как известно, неэффективно. Право может не придать такому договору идеальный - юридический - эффект, обязательство не возникнет без необходимого «юридического состава».

16 Формально п. 3 ст. 154 ГК РФ говорит: «Для заключения договора необходимо выражение согласованной воли двух сторон (двусторонняя сделка) либо трех или более сторон (многосторонняя сделка)». И ничего, кроме волеизъявлений, не требуется.

17 Существуют также такие конструкции соглашений, при которых юридический эфффект обусловлен бо́льшим количеством юридических фрактов. Так, реальное дарение предприятия считается заключенным с момента государственной регистрации договора (п. 3 ст. 560 ГК РФ). То есть юридический состав обусловлен тремя фактами - соглашением, передачей и государственной регистрацией. Правовая природа всех трех фактов различна.

18 «Заключен» здесь употребляется в том смысле, что стороны обменивались волеизъявлениями: был акцепт и офрерта - ставили подписи на договоре, произносили слова и т. п. лишь фрактическим действием. Такой договор ничтожен ${ }^{19}$ (лат. nullus, нем. nichtig), не существует, в праве - системе абстрактных связей - ничего не изменяется, как будто бы волеизъявления не было 20 .

В случае если реального акта (передачи) никогда не произойдет, то юридического эфффекта сделка никогда не получит. Если же эффрект произойдет, то сделка будет иметь силу. Эффект здесь подобный тому, который имеется в сделках, совершенных под отлагательным условием.

В общем виде предписание закона для реального договора таково: договор будет иметь силу с момента осуществления реального акта. Таким образом, воля на достижение правового эффректа заключается здесь не в реальном акте, а в сделке, эфффект которой «отодвинут» законом ${ }^{21}$. Отличие от сделки под отлагательным условием заключается в том, что в реальном договоре эффрект сделки наступает в момент передачи вещи (сейчас (лат. ex nunc)), тогда как в сделке, совершенной под отлагательным условием, эфрфект сделки наступает в момент совершения сделки (тогда (лат. ex tunc)). Однако в реальном договоре все же применяются условия, выраженные в сделке при совершении "обмена волеизъявлениями», а не в момент передачи, что еще раз доказывает, что до передачи сделка заключена, но не порождает правового эфффекта.

Условием, как известно, является обстоятельство реальной действительности, относительно которого неизвестно, наступит оно или нет. В определенных типах правоотношений законодатель видит необ-

${ }^{19}$ Ничтожность здесь понимается в ее классическом смысле, не имеющем ничего общего с п. 1 ст. 166 ГК РФ $[15$, S. $221 ; 16$, S. 200].

${ }^{20}$ Сделка есть, но считается, что нет, применяется юридическая фикция. Собственно, такая фикция необходима именно потому, что действие есть то, чего по факту нет, никогда не порождает эффректа, напротив, отрицать объективное - бессмысленно. Причем данный юридический прием стал возможным на довольно позднем этапе развития римского права, когда эфффект сделки (частного закона (лат. lex privata)) можно отменять законом публичным (установленным государством) (лат. lex publica). Такой эффрект возможен только благодаря появлению законов совершенного вида (лат. leges perfectae). Интересно, что правопорядок изначально наделяет частные волеизъявления определенного типа "силой», а после лишает те из них, которые не удовлетворяют определенным требованиям leges perfectae, этой силы.

${ }^{21} \mathrm{C}$ точки зрения учения об условных сделках такое условие должно квалифицироваться как законное (лат. conditio iuris) и смешанное. Вряд ли его можно считать чисто потестативным, поскольку передача вещи не может полностью зависеть от усмотрения передающего: вещь может погибнуть и нечего будет передавать. 
ходимость в передаче вещи для того, чтобы сделка порождала правовые последствия, не придавая юридического эфффекта «голым» волеизъявлениям. При этом для действительности реального договора не требуется фактического вручения вещи, если вещь уже находится у одаряемого, хранителя и т. п., в данном случае достаточно лишь собственно волеизъявления (изменение основания). Например, держатель был арендатор, стал одаряемый, был находчик, стал хранитель и т. п., так называемая передача короткой рукой (лат. traditio brevi manu). Таким образом, для реального договора передача является элементом внешним и определяет лишь момент вступления в силу такого договора.

Поскольку передача не является структурным элементом реального договора, утверждение о том, что такая передача имеет несделочную природу, уже не кажется противоречивым.

Основным аргументом сторонников сделочной природы передачи вещи является то обстоятельство, что при передаче вещи необходимо согласование воли передающего вещь (традента) и принимающего вещь (акципиента), направленность их воли на достижение правового результата и правомерность такой передачи [4, с. 48].

Как представляется, неправильное понимание правовой природы действий по передаче вещи в реальном договоре связано с недостатками учения о юридических фрактах, а именно с нечетким разграничением юридических действий. В таких условиях, когда ни юридические акты, ни юридические поступки не обладают достаточно определенными признаками и критериями разграничения, не представляется возможным и причисление к этим конструкциям отдельных разновидностей юридических фактов.

С точки зрения классификации юридических фрактов по волевому признаку передача вещи в реальном договоре, несомненно, является юридическим действием. Трудности в квалификации данного вида юридического факта появляются на следующем этапе классификации - при делении действий на юридические акты и поступки 22 .

Как отмечалось нами ранее [17; 18], в литературе отсутствует единый критерий, позволяющий провести разграничение между юридическими актами и юридическими поступками. Нами выбран критерий — фор-

${ }^{22}$ Кроме того, применительно к обсуждаемому юридическому составу - реальный договор, передача является правопорождающим юридическим фактом, т. е. возникают права и обязанности. ма выражения воли в юридическом действии. Юридическим поступком, в нашем понимании, является влекущее правовые последствия явление реальной действительности, существующее в фрорме активных физических, материальных, утилитарных (полезных) действий или творческой деятельности, воздействующих на объект гражданских прав, в результате совершения которых происходит возникновение этого объекта, его прекращение или изменение каких-либо его характеристик и свойств. В отличие от них юридические акты совершаются в фрорме волеизъявлений, являются коммуникативными, неутилитарными (неполезными) и воздействуют исключительно на волю иных субъектов гражданского оборота [17, с. 153-154].

Юридические поступки обладают следующими признаками:

1. Воздействуют на объекты гражданских прав.

2. Совершаются в форме активных (положительных) фризических (материальных) действий либо интеллектуальной (творческой) деятельности, требующих приложения соответственно физического или интеллектуального усилия и не являющихся волеизъявлениями, направленными на восприятие другим лицом (лицами): не направлены «на общение», при этом являясь проявлениями воли в иной фрорме.

3. Совершение юридического поступка приводит к достижению свойственного только ему результата - к переменам в объектах гражданских прав (возникновение, изменение свойств или формы объекта, его положения в пространстве ит. п.).

Кроме перечисленных признаков, юридическим поступкам также свойственны такие характерные черты, как достижение «фактической (экономической) цели» непосредственно и, как следствие, относящихсяк «миру фактических», а не «юридических действий»; они являются, как правило, «материальными» действиями, воздействующими на предметы материального мира путем приложения фризического усилия, а не путем произнесения слов (или знаков речи в иной форме).

Передача - действие активное, требующее приложения фризического усилия, воздействует на объект гражданских прав (перемещает его в пространстве, изменяется лицо, обладающее контролем над объектом и т. п.). Этим передача в значительной степени отличается от юридических актов [19].

Кроме того, реальный акт не содержит в своем составе волеизъявления, направленного на создание правовых последствий, 
оно уже совершено в другом юридическом акте - консенсусе, в повторном волеизъявлении ни стороны, ни правопорядок не нуждаются [8, с. 23].

К. И. Скловский на примере дарения совершенно точно заметил, что «суть дарения как сделки состоит в том, что одна сторона попросила вещь, а другая согласилась ее отдать, причем обе стороны согласились (договорились), что если вещь будет передана, то даритель потеряет право собственности на нее, как только она будет получена одаряемым. Все содержание - воля на отчуждение и согласие на приобретение - заключено в договоре, передача ничего к этому не добавляет» [там же].

Правовая природа правопорождающей и правопрекращающей передачи с точки зрения классификации юридических фактов по волевому признаку, по нашему мнению, одинакова, поэтому передачу вещи в реальном договоре не следует считать юридическим актом. Такая передача, так же как передача вещи во исполнение обязательства, является юридическим поступком [19]. В противном случае следовало бы признать, что передача вещи в реальном договоре отличается от передачи вещи в консенсуальном договоре, что вело бы к логическому противоречию, поскольку сущностные характеристики передачи вещи как юридического действия воля, направленность воли, фрорма совершения - не могут поменяться в результате изменения основания передачи [8, с. 24].

Стоит также заметить, что к передаче вещи совершенно не применимы нормы законодательства, применимые к юридическим актам (даже по аналогии). Связано это с тем, что существо передачи вещи и юридических актов (в том числе сделок) значительно различается. Так, сложно себе представить, чтобы передача вещи была признана недействительной - в этом случае она не порождала бы никаких правовых последствий, однако аннулирование действия (недействительность) доступно только для таких действий, которые ничего, кроме собственно юридического эфрфекта, не создают, т. е. только для юридических актов. Передача вещи под условием, как представляется, также невозможна: вещь передается в момент «фактического вручения» в соответствии со ст. 224 ГК РФ, отложить же эфрфект вручения вещи невозможно, возможно лишь отодвинуть переход права собственности в соответствии с п. 1 ст. 223 ГК РФ. Отменительное условие для передачи вещи также невозможно: если вещь передана в собственность, то с наступлением условия ни вещь автоматически не возвращается траденту, ни право собственности (прекращается только установленными в законе способами - ст. 235 ГК РФ). Поскольку передача вещи осуществляется в единственно возможной форме - фактического вручения, то, разумеется, нормы о форме совершения юридических актов к передаче не могут применяться (она не бывает ни устной, ни письменной).

Таким образом, реальный договор состоит из соглашения и реального акта (юридического поступка) - передачи вещи. Так, Е. Я. Мотовиловкер совершенно точно утверждает, что традиция не входит в состав реального договора, а является самостоятельным юридическим фактом, с моментом совершения которого связываются определенные правовые последствия [2, с. 90-94].

Передача вещи устанавливает «фрактическое господство» лица, которому вещь передана, - с этого момента приобретатель получает абсолютную позицию против всех третьих лиц. Такой эффрект возможен благодаря тому, что данное действие является материальным (утилитарным), в отличие от юридических актов, производящих перемены только в идеальной (юридической, неутилитарной) сорере.

Передача вещи в реальном договоре непосредственно позволяет сторонам достичь того «экономического» эффеекта, к которому они стремились, - передать и получить вещь. Такой результат действия характерен только для юридических поступков [18].

Таким образом, фактический состав реального договора состоит из совокупности юридических фактов - соглашения, являющегося по правовой природе сделкой, и передачи вещи, являющейся юридическим поступком.

\section{СПИСОК ИСПОЛЬЗОВАННОЙ ЛИТЕРАТУРЫ}

1. Грачев В.В.Правовая природа традиции / В.В.Грачев / / Сборник статей к 55-летию Е. А. Крашенинникова : сб. науч. тр. / под ред. П. А. Варул. - Ярославль : ЯрГУ, 2006. - С. 16-35.

2. Мотовиловкер Е. Я. Спорные вопросы теории сделок / Е. Я. Мотовиловкер // Вестник гражданского права. - 2011. - Т. 11, № 4. - С. 84-101.

3. Груздев В. В. Реальные договоры в российском гражданском праве / В. В. Груздев // Право и экономика. - 2001. - № 1. - С. 15-18.

4. Сарбаш С. В. Исполнение договорного обязательства / С. В. Сарбаш. - М. : Статут, 2005. - 636 с. 
5. Бутакова Н. А. Реальный и консенсуальный договор [Электронный ресурс] / Н. А. Бутакова // СПС «КонсультантПлюс».

6. Дождев Д. В. Римское частное право : учебник / Д. В. Дождев ; под ред. В. С. Нерсесянца. - 2-е изд., изм. и доп. - М. : Норма, 2005. - 784 с. $584 \mathrm{c}$

7. Дигесты Юстиниана : пер. с лат. / под ред. Л. Л. Кофанова. - М. : Статут, 2002. - Т. 1, кн. 1-4. -

8. Скловский К. И. Сделка и ее действие. Комментарий главы 9 ГК РФ (Понятие, виды и форма сделок. Недействительность сделок) / К. И. Скловский. - 2-е изд. - М. : Статут, 2016. - 176 с.

9. Тузов Д. О. Теория недействительности сделок: опыт российского права в контексте европейской правовой традиции / Д. О. Тузов. - М. : Статут, 2007. - 602 с.

10. Хаскельберг Б. Л. Консенсуальные и реальные договоры в гражданском праве / Б. Л. Хаскельберг, В. В. Ровный. - 2-е изд., испр. - М. : Статут, 2004. - 124 с.

11. Хаскельберг Б. Л. К вопросу о правовой природе традиции / Б. Л. Хаскельберг / / Сборник статей к 55-летию Е. А. Крашенинникова : сб. науч. тр. / под ред. П. А. Варул. — Ярославль : ЯрГУ, 2006. - С. 120-136.

12. Kunze E. lusta causa traditionis oder das Abstraktionsprinzip im römischen Recht : Exegese zu D. 41.1.36 nebst der Antinomie zu D. 12.1.18 pr. / E. Kunze. - München : GRIN Verlag GmbH, 2009. — 33 S.

13. Церковников М. А. Признание договора незаключенным. Когда суд сохранит договорные отношения / М. А. Церковников / / Арбитражная практика. - 2014. - № 5. - С. 20-28.

14. Варул П. А. Волеизъявление и сделка / П. А. Варул, Л. Я. Халлик // Сборник статей к 55-летию Е. А. Крашенинникова : сб. науч. тр. / отв. ред. П. А. Варул. - Ярославль : ЯрГУ, 2006. - С. 7-15.

15. Savigny F. K. von. System des heutigen r mischen Rechts / F. K. von Savigny. - 2. Ausg. — Darmstadt : Gentner, 1956. - 540 S.

16. Windscheid B. Lehrbuch des Pandektenrechts / B. Windscheid. - Düsseldorf : Verlagshandlung von Julius Buddeus, 1870. - Bd. 1. - $776 \mathrm{~S}$.

17. Титов Е. В. О понятии юридического поступка в гражданском праве / Е. В. Титов / / Реализация и защита гражданских прав и законных интересов граждан и юридических лиц в свете реформирования гражданского законодательства Российский Федерации : материалы Всерос. науч.-практ. конф. / под ред. У. Б. Филатовой. - Иркутск : Изд-во ИГУ, 2014. - С. 151-156.

18. Титов Е. В. Юридические действия, квалифицируемые в качестве юридических поступков / Е. В. Титов / / Пролог. - 2014. - Т. 2, № 4. - С. 68-72.

19. Титов Е. В. Правовая природа исполнения обязательства / Е. В. Титов / / Baikal Research Journal. 2016. — T. 7, № 3. - DOI: 10.17150/2411-6262.2016.7(3).24.

\section{REFERENCES}

1. Grachev V. V. The Legal nature of Tradition. In Varul P. A. (ed.). Sbornik statei k 55-letiyu E. A. Krasheninnikova [Collected Papers for the $55^{\text {th }}$ Anniversary of E. A. Krasheninnikov]. Yaroslavl State University Publ., 2006, pp. 16-35. (In Russian).

2. Motovilovker E. Ya. Controversial Issues of the Theory of Transactions. Vestnik grazhdanskogo prava = Civil law review, 2011, vol. 11, no. 4, pp. 84-101. (In Russian).

3. Gruzdev V. V. Real Contracts in the Russian Civil Law. Pravo i ekonomika = Law and Economics, 2001, no. 1, pp. 15-18. (In Russian).

4. Sarbash S. V. Ispolnenie dogovornogo obyazatel'stva [Performance of a Contractual Obligation]. Moscow, Statut Publ., 2005. 636 p.

5. Butakova N. A. Real'nyi i konsensual'nyi dogovor [Real and Consensual Contract], 2017. Available at: http: // www.consultant.ru. (In Russian).

6. Dozhdev D. V.; Nersesyants V. S. (ed.). Rimskoe chastnoe pravo [Roman Private Law]. $2^{\text {nd }}$ ed. Moscow, Norma Publ., 2005. 784 p.

7. Kruegero Paulo, Mommsen Th. Digesta lustiniani Augusti recognouit adsumpto in operis societatem. Berolini, 1870, vol. 1. (Russ. ed.: Kofanov L. L. (ed.). Digesty Yustiniana. Moscow, Statut Publ., 2002. Vol. 1, pt. 1-4. 584 p.).

8. Sklovskii K. I. Sdelka i ee deistvie. Kommentarii glavy 9 GK RF (Ponyatie, vidy i forma sdelok. Nedeistvitel' nost' sdelok) [The Transaction and Its Operation. Comment of Chapter 9 of the Civil Code of the Russian Federation (Concept, Types and Form of Transactions: Invalidity of Transactions)]. $2^{\text {nd }}$ ed. Moscow, Statut Publ., 2016. 176 p.

9. Tuzov D. O. Teoriya nedeistvitel'nosti sdelok: opyt rossiiskogo prava v kontekste evropeiskoi pravovoi traditsii [The Theory of Invalidity of Transactions: the experience of Russian law in the context of the European legal tradition]. Moscow, Statut Publ., 2007.602 p.

10. Khaskel'berg B. L., Rovnyi V. V. Konsensual'nye i real'nye dogovory v grazhdanskom prave [Consensual and Real Contracts in Civil Law]. $2^{\text {nd }}$ ed. Moscow, Statut Publ., 2004. 124 p.

11. Khaskel'berg B. L. On the Legal Nature of Tradition. In Varul P. A. (ed.). Sbornik statei k 55-letiyu E. A. Krasheninnikova [Collected Papers for the $55^{\text {th }}$ Anniversary of E. A. Krasheninnikov]. Yaroslavl State University Publ., 2006, pp. 120-136.

12. Kunze E. lusta causa traditionis oder das Abstraktionsprinzip im römischen Recht: Exegese zu D. 41.1.36 nebst der Antinomie zu D. 12.1.18 pr. München, GRIN Verlag GmbH, 2009. 33 S.

13. Tserkovnikov M. A. Acknowledgement of a Loss of a Contract. When the Court Retains Contractual Relations. Arbitrazhnaya praktika = Arbitrage Practice, 2014, no. 5, pp. 20-28. (In Russian).

14. Varul P. A., Khallik L. Ya. Declaration of Will and the Transaction. In Varul P. A. (ed.). Sbornik statei k 55-letiyu E. A. Krasheninnikova [Collected Papers for the $55^{\text {th }}$ Anniversary of E. A. Krasheninnikov]. Yaroslavl State University Publ., 2006, pp. 7-15. 
15. Savigny F. K. von. System des heutigen römischen Rechts. $2^{\text {nd }}$ ed. Darmstadt, Gentner, 1956.540 p.

16. Windscheid B. Lehrbuch des Pandektenrechts. Düsseldorf, Verlagshandlung von Julius Buddeus, 1870. Bd. 1. $776 \mathrm{~S}$.

17. Titov E. V.; Filatova U. B. (ed.). On the Notion of Legal Act in Civil Law. Realizatsiya i zashchita grazhdanskikh prav i zakonnykh interesov grazhdan i yuridicheskikh lits v svete reformirovaniya grazhdanskogo zakonodatel'stva Rossiiskii Federatsii. Materialy Vserossiiskoi nauchno-prakticheskoi konferentsii [Enforcement and Protection of Civil Rights and Legitimate Interests of citizens and Legal Entities in the Context of Reforming of the Russian Civil Legislation . Materials of the Russian National Research Conference]. Irkutsk State University Publ., 2014, pp. 151-156. (In Russian).

18. Titov E. V. Legal actions classified as legal deeds. Prolog = Prologue, 2014, vol. 2, no. 4, pp. 68-72. (In Russian).

19. Titov Ye. V. Legal nature of enforcing the obligation. Baikal Research Journal, 2016, vol. 7, no. 3. DOI: 10.17150/2411-6262.2016.7(3).24. (In Russian).

\section{Информация об авторах}

Ламм Татьяна Валерьевна - кандидат юридических наук, доцент, кафедра гражданского права и процесса, Байкальский государственный университет, 664003, г. Иркутск, ул. Ленина, 11, e-mail: gtlamm@narod.ru.

Титов Евгений Валерьевич - ассистент, кафедра гражданского права и процесса, Байкальский государственный университет, 664003, г. Иркутск, ул. Ленина, 11, e-mail: bumbala@mail.ru.

\section{Для цитирования}

Ламм Т. В. Правовая природа передачи вещи как элемента фактического состава реального договора / Т. В. Ламм, Е. В. Титов // Известия Байкальского государственного университета. - 2017. - T. 27, № 4. - C. 546-553. - DOI: $10.17150 / 2500-2759.2017 .27(4) .546-553$.

\section{Authors}

Tatyana V. Lamm - PhD in Law, Associate Professor, Department of Civil Law and Procedure, Baikal State University, 11 Lenin St., 664003, Irkutsk, Russian Federation, e-mail: gtlamm@narod.ru.

Eugeny V. Titov - Assistant Professor, Department of Civil Law and Procedure, Baikal State University, 11 Lenin St., 664003, Irkutsk, Russian Federation, e-mail: bumbala@mail.ru.

\section{For citation}

Lamm T. V., Titov E. V. The Legal Nature of the Transfer of Objects as an Element of the Set of Facts of the Real Contract. Izvestiya Baykal' skogo gosudarstvennogo universiteta $=$ Bulletin of Baikal State University, 2017, vol. 27, no. 4, pp. 546-553. DOI: $10.17150 / 2500-$ 2759.2017.27.(4).546-553. (In Russian). 